\title{
Representações Sociais acerca do Trabalho em Equipe
}

Social Representations about Teamwork Representaciones Sociales acerca del Trabajo en Equipo

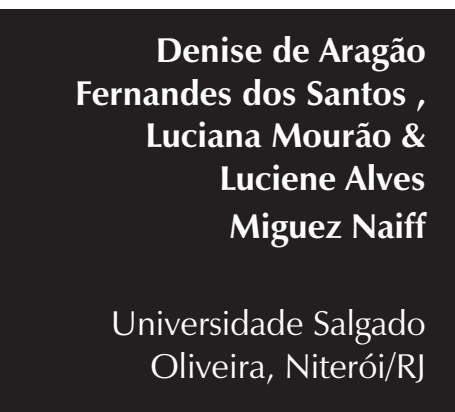

http://dx.doi.org/10.1590 / 1982 - 3703000802013

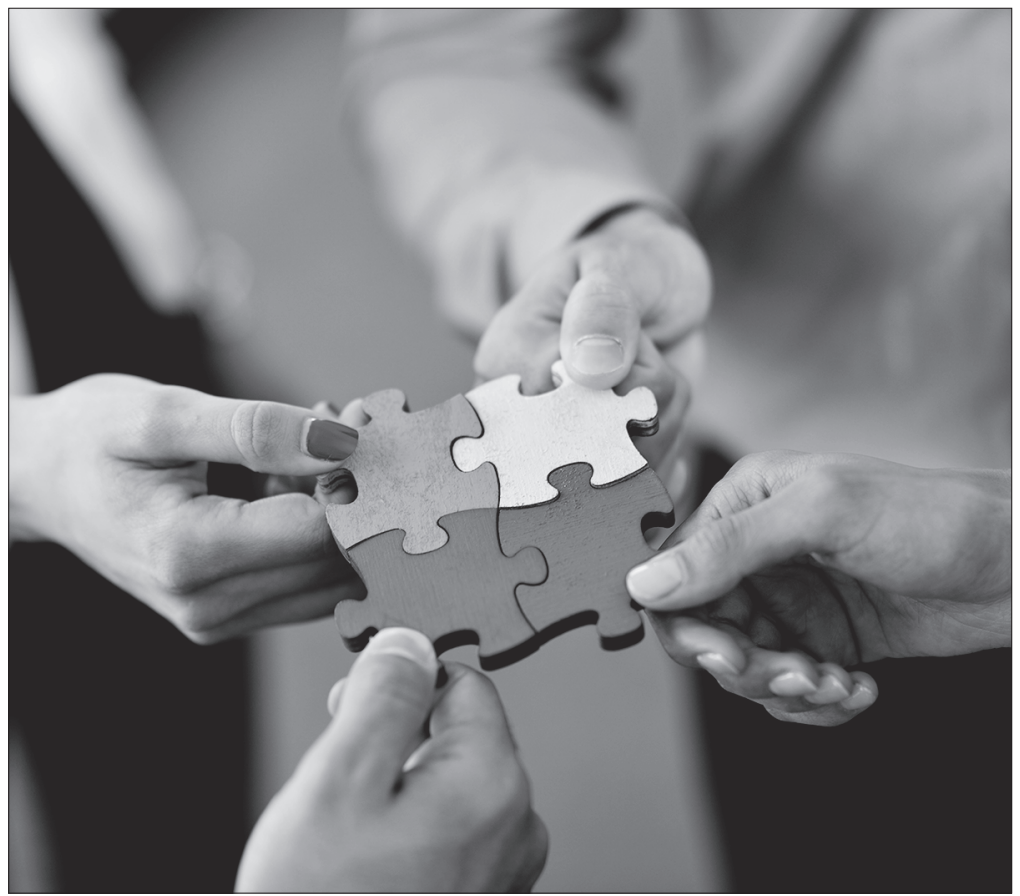


Resumo: O trabalho em equipe é uma demanda das atuais organizações de trabalho. Este estudo identificou representações sociais acerca do trabalho em equipe em universidades no Rio de Janeiro. Uma fase inicial de evocação foi feita com 134 funcionários, que indicaram e ordenaram de três a cinco palavras a partir do termo indutor "trabalho em equipe". Na sequência, foram realizadas 14 entrevistas para aprofundamento das respostas. A abordagem de representações sociais escolhida foi a estrutural, de Jean Claude Abric e a análise foi feita com apoio do software EVOC. Os resultados indicam 393 palavras evocadas, sendo 187 distintas, cujo agrupamento por semelhança resultou em 105 palavras/expressões. Os resultados apontam como possíveis núcleos centrais as palavras "respeito", "união" e "cooperação". Os resultados foram discutidos à luz da literatura, sendo apresentadas contribuições do estudo para o avanço das pesquisas sobre equipes de trabalho.

Palavras-chave: Organização do trabalho. Comportamento organizacional. Trabalho em equipe. Representação social.

Abstract: Teamwork is a demand of current labor organizations. This study identified social representations about teamwork at universities in Rio de Janeiro. An initial phase of evocation was made with 134 employees, which indicated and ordered three to five words from the inductor term "teamwork". As a result, 14 interviews were held to deepen the answers. The social representations approach that was chosen was structural, of Jean Claude Abric, and the analysis was made with the support of EVOC software. The results indicate 393 words evoked, 187 are different, whose grouping by similarity resulted in 105 words/expressions. The results show that possible central cores words are "respect", "unity" and "cooperation". The results were discussed in the light of literature, presenting the study's contributions to the advancement of research on work teams.

Keywords: Work organization. Organizational behavior. Teamwork. Social representation .

Resumen: El trabajo en equipo es una demanda de las actuales organizaciones de trabajo. Este estudio identificó representaciones sociales acerca del trabajo en equipo en universidades en Rio de Janeiro. Una fase inicial de evocación fue efectuada con 134 funcionarios, que indicaron y ordenaron de tres a cinco palabras a partir del término inductor "trabajo en equipo". A continuación, fueron realizadas 14 entrevistas para profundización de las respuestas. El abordaje de representaciones sociales escogido fue el estructural, de Jean Claude Abric y el análisis fue efectuado con apoyo del software EVOC. Los resultados indican 393 palabras evocadas, siendo 187 distintas, cuyo agrupamiento por semejanza resultó en 105 palabras/expresiones. Los resultados apuntan como posibles núcleos centrales las palabras "respeto", "unión" y "cooperación". Los resultados fueron discutidos a la luz de la literatura, siendo presentadas contribuciones del estudio para el avance de las pesquisas sobre equipos de trabajo.

Palabras clave: Organizacion del trabajo. Comportamiento organizacional. Trabajo en equipo. Representacion social 
As demandas que se impõem para as organizações modernas dificilmente poderiam ser atendidas com as competências individuais de um ou outro empregado. É preciso que haja um conjunto de pessoas trabaIhando de forma interdependente para que se consiga atingir boa parte das metas que são estabelecidas para as células, sejam elas setores, departamentos, superintendências ou qualquer outro tipo de organização funcional.

Além disso, no atual mundo do trabalho, é cada vez menos comum as pessoas trabalharem na mesma organização por vários anos. Nesse sentido, há uma preocupação das organizações em estruturar o trabalho em equipe para que haja menos perdas de know-how em função da rotatividade de empregados. As equipes de trabalho caracterizam-se, portanto, como uma demanda das organizações atuais que necessitam propiciar o desenvolvimento de ideias criativas e compartilhamento do conhecimento.

O desempenho exigido atualmente inclui múltiplas habilidades, capacidade de julgamento e experiências diversas. Assim, acredita-se que as equipes são necessárias em função de elas superarem o desempenho de pessoas que atuam sozinhas ou em meio a agrupamentos organizacionais fomentando habilidades múltiplas, experiências diversificadas e trabalhos complexos (Katzenbach \& Smith, 2001).

Assim, o estudo das equipes assume, atualmente, um papel relevante na investigação organizacional, quer na literatura conceitual, quer nos estudos empíricos (Hoegl \& Parboteeah, 2006). As demandas que se impõem às células de trabalho das organizações modernas dificilmente poderiam ser atendidas com as competências individuais de um ou outro empregado. É preciso que haja um conjunto de pessoas trabalhando de forma interdependente para que se consiga atingir boa parte das metas.

Diante desse cenário, fica evidente a demanda por parte das organizações de estudos acerca do trabalho em equipe. Diante de toda essa hipervalorização do trabalho em equipe, cabe perguntar: $E$ os trabalhadores, o que pensam e partilham socialmente acerca do trabalho em equipe?

Este estudo buscou investigar o que as pessoas pensam acerca do trabalho em equipe e que elementos evocam ao tratar desse tema. Assim, o objetivo do presente estudo foi identificar as representações sociais acerca do trabalho em equipe em universidades do estado do Rio de Janeiro.

\section{Equipes de trabalho}

As equipes de trabalho constituem uma temática abordada por diferentes autores. Alguns abordam diretamente a expressão "equipes de trabalho", outros falam em "trabalho em equipe" e há ainda os que se referem simplesmente a "equipes" mantendo-se alguns elementos presentes em várias definições, enquanto outros são específicos de algumas delas.

O elemento "objetivos/propósitos compartilhados/comuns" é mencionado nas definições de: Moscovici (1994), Arrow e McGrath (1995), Katzenbach e Smith (2001) e Sikes, Gulbro e Shonesy (2010). Outro elemento presente na definição de equipes é o "desempenho/resultados", que surge nas definições de: Hackman (1987), Moscovici (1994), Guzzo e Dickson (1996) e Guerra (2002). Por fim, outro elemento comum às definições é o elemento "pessoas/indivíduos/membros", que aparece em todos os conceitos apresentados na Tabela 1, exceto no de Hackman (1987). 
Tabela 1.

Definições de equipes de trabalho

Autor

Definição de equipes

Hackman (1987)

Equipes de trabalho podem ser definidas como entidades sociais inseridas em sistemas maiores, as quais executam tarefas consideradas relevantes para a missão da organização à qual pertencem, uma vez que os seus resultados de desempenho têm consequências para o ambiente interno e externo à equipe.

Moscovici (1994)

Pode-se considerar equipe um grupo que compreende seus objetivos e está engajado em alcançá-los, de forma compartilhada. A comunicação entre seus membros é verdadeira, opiniões divergentes são estimuladas. A confiança é grande, assumem-se riscos. As habilidades complementares dos membros possibilitam alcançar resultados, os objetivos compartilhados determinam seu propósito e direção. Respeito, mente aberta e cooperação são elevados. O grupo investe constantemente em seu próprio crescimento.

Arrow e McGrath

Equipes são um padrão complexo de relações dinâmicas entre um con(1995) junto de membros que utilizam determinada tecnologia para atingir propósitos comuns.

Guzzo e Dickson (1996)

Katzenbach e Smith (2001)

Guerra (2002)

Rodrigues, Johann, Cunha, \& Macêdo (2003)

Sikes, Gulbro e Shonesy (2010)
Equipe refere-se a indivíduos que se percebem e são percebidos pelos outros como uma entidade social, interdependentes por causa das tarefas que desempenham e inseridos em um sistema maior, a organização, que é afetada pelo desempenho do grupo.

Equipe deve ser formada por um pequeno grupo de pessoas com habilidades complementares igualmente comprometidas com um objetivo, metas e uma abordagem de trabalho comuns, pelos quais todos os integrantes se considerarão mutuamente responsáveis.

O trabalho em equipe compreende um conjunto de comportamentos que são, simultaneamente, desconhecidos e difíceis de pôr em prática, dia após dia, mas que contribui para o alcance dos resultados organizacionais à medida que potencializa a capacidade de inovar e solucionar problemas por meio de atitudes colaborativas dos membros da equipe.

Um conjunto de pessoas com habilidades complementares, atuando juntas numa mesma atividade, com propósitos e objetivos comuns, comprometidas umas com as outras e com qualidade dos relacionamentos e dos resultados.

Equipe de trabalho é um grupo organizado, comprometido com os indivíduos, cujos membros compartilham a mesma intenção de realizar um objetivo comum.

Como pode ser observado, alguns autores apresentam definições bastantes técnicas como as de Hackman (1987), Arrow e McGrath (1995) e Guzzo e Dickson (1996). Por outro lado, a definição de alguns autores apresenta uma realidade bastante romanceada em que se espera um extenso - e nem sempre alcançável - conjunto de atributos positivos para as equipes de trabalho, como as de Katzenbach e Smith (2001) e Moscovici (1994), sobretudo neste último. Por fim, há autores que apresentam uma visão crítica e ressaltam as dificuldades das equipes de trabalho em sua própria definição do termo como é o caso de Guerra (2002). 
Para o presente estudo, foi considerada como referência de definição aquela apresentada por Katzenbach e Smith (2001), por ser uma definição simples e que aborda quatro elementos considerados fundamentais: (a) as habilidades complementares; (b) o comprometimento com um objetivo; (c) uma abordagem de trabalho comum; e (d) a responsabilidade compartilhada.

Em relação aos estudos empíricos, optou-se por fazer uma revisão dos estudos nacionais, uma vez que as representações sociais sobre o trabalho em equipe podem ser muito influenciadas por aspectos culturais já que as vivências das pessoas no ambiente de trabalho podem ser muito distintas dependendo de onde aconteçam. Tais pesquisas serão sucintamente apresentadas a seguir, seguindo-se a ordem cronológica de publicação.

A pesquisa de Puente-Palacios e Borges-Andrade (2005) baseou-se no modelo teórico de Guzzo e Shea (1992) e explorou a temática efetividade das equipes utilizando um modelo multinível e investigando a interdependência de tarefas, de resultados e as crenças na efetividade das equipes. Como indicador da efetividade foi considerado a satisfação dos membros. A amostra levou em conta 28 equipes de trabalho (com um total de 113 indivíduos). Foi verificada diferença nos resultados entre indivíduos e equipes, o que reforça a importância de utilização de modelos multinível nesse tipo de investigação. Os resultados da pesquisa apontam que, dentre os indivíduos que consideram as equipes de trabalho efetivas, a satisfação está positivamente relacionada à dependência dos seus colegas para atingir resultados. O contrário acontece entre aqueles que não acreditam na efetividade das equipes.

O estudo de Bejarano, Pilatti, Scandelari e Oliveira (2006) foi realizado em uma empresa têxtil com o objetivo de analisar as variáveis que podem interferir na implementação e no êxito de equipes virtuais. Os autores realizaram um estudo de caso a partir de observação participante, análise documental e questionários com os membros da equipe virtual. Os resultados mostram que nos relacionamentos intermediados por tecnologia, os problemas de comunicação podem ser maximizados. Isto significa que as equipes unicamente virtuais podem ter maiores problemas na comunicação de seus membros, o que compromete a eficácia das interações e da equipe.

Mourão e Galinkin (2008) realizaram um estudo que teve como objetivo apreender a maneira como as equipes que têm uma mulher como gerente estão construindo percepções sobre esse gerenciar, tendo como base a teoria das representações sociais. Participaram 74 mulheres e 72 homens de equipes que trabaIham com sete mulheres da alta gestão da Administração Pública Federal. Os resultados da pesquisa indicam que as equipes que trabalham com mulheres gerentes no Serviço Público Federal apresentam como características: organização, compreensão, flexibilidade e competência, que são as expressões que compõem o provável núcleo central derivado da análise de resultados. Os resultados mostram que há uma percepção dos membros das equipes de que a gestão feita por mulheres é voltada para as relações pessoais, respeito pela individualidade e preocupação com a qualidade do trabalho. O excesso de preocupação com detalhes é observado também, como característica de desempenho, sugerindo mais um defeito que uma qualidade das gestões femininas. Vale destacar que a competência é indicada como desvinculada do sexo de quem gerencia, sendo atribuída às características individuais de gerenciamento.

O estudo de Matos, Pires e Campos (2009) objetivou analisar a importância de equipes interdisciplinares na área da saúde e foi realizado em dois hospitais públicos na região Sul do Brasil, considerados como referências em suas áreas de atuação. Participaram do estudo 19 representantes das diferentes categorias profissionais que integram as equipes estudadas, sendo utilizadas como técnicas de coleta de dados entrevistas semiestruturadas e observação sistemática das atividades realizadas pelas equipes. Em relação à inte- 
ração, à articulação e ao poder nas relações profissionais, os integrantes do estudo revelaram que as relações de trabalho são satisfatórias, constituindo-se em um dos fatores que mais motivam a sua permanência nas equipes, especialmente quando comparadas às relações vivenciadas em outros espaços e equipes. Os resultados revelaram ainda que a perspectiva interdisciplinar do trabalho em equipe possibilita melhores relações de trabalho entre profissionais e entre eles, os pacientes e familiares, contribuindo para meIhores resultados de trabalho.

A pesquisa realizada por Brandt e Oliveira (2009) apresenta uma análise das relações dos supervisores com os membros de suas equipes nas organizações de trabalho públicas e privadas. Os pesquisadores optaram por trabalhar com grupos constituídos exclusivamente de profissionais que exercem cargos de chefia com experiência mínima de dois anos. O trabalho de abordagem psicossocial e psicanalítica foi realizado em dez encontros semanais com duração de 1h30min cada, nos quais os participantes relatavam experiências difíceis vivenciadas com seus subordinados. Foram realizadas duas experiências, cada uma com 28 participantes de organizações públicas e privadas. Havia um repetido movimento grupal que inicialmente colocava a culpa das relações conflituosas no subordinado e, a partir da elaboração grupal, as projeções defensivas eram deslocadas para as dificuldades da organização e, finalmente, o grupo refletia sobre as próprias dificuldades. Os pesquisadores concluíram que a maioria dos participantes, apesar das pressões cotidianas, consegue manter-se no campo da "normalidade", apesar dos sofrimentos e das estratégias defensivas. Observou-se, na avaliação final dos encontros, que os profissionais relatam alívio ao perceberem que não há respostas certas e que cada um acaba encontrando o seu próprio caminho na gestão das relações interpessoais nas equipes de trabalho.

O estudo realizado por Marqui et al. (2010) objetivou conhecer as características das equipes da Estratégia de Saúde da Família (ESF) no Rio Grande do Sul e identificar suas dificuldades e os processo de trabalho. A pesquisa foi qualitativa, da forma exploratório-descritiva, com aplicação de questionários a 126 trabalhadores de 26 municípios e 39 equipes de saúde da família. Os membros que compõem as equipes pesquisadas são predominantemente jovens, mulheres e com formação profissional recente. Os pesquisadores identificaram algumas dificuldades nos processos de trabalho, dentre as quais estão: a dificuldade de trabalhar em equipe, entendimento equivocado dos gestores, profissionais sem perfil, falta de integração dos gestores, equipe e comunidade e a falta de especialização dos trabalhadores. Também foram apontadas dificuldades específicas do trabalho na Estratégia de Saúde da Família. Vale ressaltar que $17 \%$ dos pesquisados relataram dificuldades no trabalho em equipe, as quais foram associadas a: (a) falta de planejamento dos membros para o trabalho coletivo; (b) falta de sensibilização e interação das pessoas para o trabalho em equipe; (c) individualização do trabalho, caracterizando uma compartimentalização das atividades; e (d) dificuldade no fluxo de informações.

O foco central da pesquisa de Silva (2009) foi desenvolver e testar empiricamente um modelo teórico-explicativo do papel do conflito na efetividade das equipes de trabalho. Para tanto, foi construída e validada uma escala de mensuração de conflitos intragrupos, com 200 trabalhadores, estudantes de graduação e pós-graduação do Distrito Federal. O estudo também testou a relação entre interdependência de tarefas, resultados e conflitos. Posteriormente, analisou a relação de conflitos, satisfação e comprometimento de 125 policiais que faziam parte de 25 equipes da Polícia Federal de Brasília. Em termos gerais, observou-se que equipes que percebem depender positivamente dos seus pares para atingir resultados de desempenho, demonstraram menores níveis de conflito. Nesse sentido, a autora esclarece que os interesses e competições individuais se tornaram menores frente aos interesses do grupo, sendo 
essas ações administradas por meio de práticas cooperativas no ambiente de trabalho. Entretanto, os resultados apontaram que quanto maior a interdependência de resultados, maior também o conflito e menor a satisfação e o comprometimento dos policiais com as suas respectivas equipes de trabalho. $\mathrm{O}$ estudo desmistifica a ideia de que o conflito de relacionamento sempre impacta negativamente na efetividade das equipes. A autora conclui que se o conflito for administrado e compreendido, ele pode contribuir para as soluções de integração de interesses, diminuindo as chances do conflito de tarefas atingir níveis que possam prejudicar a efetividade das equipes.

Puente-Palacios, Almeida e Rezende (2011), por sua vez, realizaram um estudo com 333 funcionários de uma mesma organização no ramo farmacêutico no Distrito Federal, cujo objetivo foi analisar o efeito da interdependência de tarefas e de resultados sobre a satisfação e o comprometimento de membros de equipes. A pesquisa revela que existe relação entre o grau de interdependência nas equipes de trabalho e saldo afetivo dos membros (considerados pelas autoras como satisfação no trabalho e comprometimento organizacional). Nesse sentido, é ressaltado o impacto que a dependência entre os membros pode gerar na sua efetividade. $\mathrm{O}$ artigo sugere que a forma como são conduzidas as equipes de trabalho em termos da gestão da dependência dos membros para realizar tarefas, bem como da dependência deles em relação aos resultados dos colegas, pode influenciar na efetividade do trabalho da equipe e na satisfação e comprometimento desta. A proposta para uma gestão mais eficaz seria de que o grau da interdependência de tarefas e de resultados fossem simultaneamente alto ou baixo, uma vez que a percepção de interdependência de tarefas alta e de resultados baixos ou vice-versa poderia causar uma dissonância entre a realização da tarefa e o desempenho dela resultante, gerando insatisfação nos membros da equipe de trabalho.

A pesquisa de Souza e Puente-Palacios (2011) objetivou investigar a influência do auto- conceito profissional na satisfação com a equipe de trabalho. Os dados foram coletados em duas organizações privadas no ramo de tecnologia da informação em Brasília, com distribuição de um total de 1.037 questionários. A amostra contemplou participantes que pertenciam a diferentes departamentos e estavam organizados em equipes de trabalho, totalizando 373 questionários válidos. O estudo nos mostra que a autopercepção dos membros da equipe é um importante preditor da satisfação com a equipe de trabalho. As autoras analisam que a percepção de realização profissional estaria diretamente relacionada com a satisfação de necessidades individuais, o que impactaria positivamente na satisfação com a equipe. Os resultados também mostraram que a variável sexo teve efeito significativo sobre a satisfação com o trabalho em equipe, sendo que os homens tenderam a estar mais satisfeitos com as equipes que as mulheres.

Por fim, a pesquisa de Montanari, Pilatti, Lima e Romano (2011) buscou identificar a influência da maturidade das equipes no desempenho de suas atividades. A pesquisa foi realizada com sete equipes de uma prestadora de serviços, tendo sido realizadas entrevistas, observações não participantes e aplicação de dois questionários e três instrumentos. Para aprofundar a compreensão e discussão dos resultados, foi utilizada a técnica de triangulação. A investigação dos autores permitiu concluir que existe influência da maturidade no desempenho das equipes em ambiente produtivo. Os pesquisadores identificaram que essa influência se relaciona ao comportamento revelado no desempenho no grupo. Os achados mostram que, nas equipes mais maduras, os comportamentos indesejáveis ao desempenho coletivo aparecem em menor proporção que nas equipes com menor grau de maturidade.

Um olhar para esses estudos empíricos permite identificar diferenciadas frentes de pesquisa sobre equipes de trabalho. Os estudos tratam de temáticas como desempenho, efetividade, interdisciplinaridade, liderança, conflito, ques- 
tões de gênero, equipes virtuais, satisfação e comprometimento de membros de equipes.

\section{A Teoria das Representações Sociais}

A Teoria das Representações Sociais foi adotada como aporte teórico para a pesquisa, uma vez que nos interessava saber a maneira como os sujeitos sociais apreendem os acontecimentos da vida diária, as características do meio, as informações que circulam e as relações sociais relativas à temática trabalho em equipe.

As representações sociais com as quais estamos lidando no presente estudo se dividem em três grandes áreas derivadas da obra seminal de Serge Moscovici, intitulada La Psychanalyse: son image e son public de 1961, são elas: a abordagem mais clássica ainda mantida por Serge Moscovici e Denise Jodelet; a abordagem societal de Willem Doise; e a abordagem estrutural de JeanClaude Abric. Optamos por esta última para a concepção e análise no presente estudo.

Para Abric (1994), há funções essenciais nas representações sociais: (1) funções de saber (permitem compreender e explicar a realidade, fazendo a troca social, a transmissão e a difusão desse saber); (2) funções identitárias (definem a identidade e a salvaguarda da especificidade dos grupos, focando nos processos de socialização e controle social); (3) funções de orientação (guiam os comportamentos e as práticas, constituindo ações sobre a realidade); (4) funções justificatórias (permitem justificar comportamentos e decisões que foram tomadas).

De acordo com Abric (1998), o núcleo central é determinado, de um lado pela natureza do objeto representado, de outro, pelo tipo de relações que o grupo mantém com esse objeto. O núcleo central de uma representação assume, segundo o autor, duas funções fundamentais: (1) função geradora - responsável pela criação ou transformação dos outros elementos que constituem a representação, ou seja, é por meio dessa função que os outros elementos da representação ganham sentido e valor; (2) função organizadora - responsável pela unificação e estabilização da representação, uma vez que o núcleo central é responsável pela natureza dos elos, unindo os elementos da representação do objeto estudado.

Os sistemas periféricos, por sua vez, caracterizam-se por serem mais acessíveis, mais concretos, respondendo, portanto, por três funções: (1) a função de concretização que dependente do contexto, pois os elementos periféricos resultam da ancoragem da representação da realidade, sendo a interface entre o núcleo central e a situação concreta na qual a representação é colocada em funcionamento; (2) a função de regulação, uma vez que os elementos periféricos são mais leves que os centrais e exercem relevante papel na adaptação a evoluções do contexto, podendo trazer informações ou transformações do meio ambiente para a periferia da representação; (3) a função de defesa, pois o elemento periférico será o agente transformador, apresentando as contradições, novas interpretações, ou mesmo deformações funcionais defensivas, já que o núcleo central é resistente à mudança (Flament, 1994). Daí a relevância de analisar tanto o sistema central como o sistema periférico, uma vez que um complementa o outro.

Portanto, o presente estudo procurou identificar as representações sociais acerca do trabalho em equipe, levando em conta a estrutura e organização dos elementos que as compõem.

\section{Método}

O desenho metodológico definido para essa pesquisa é o de um estudo descritivo, que busca evidenciar as representações sociais acerca do trabalho em equipe. O método utilizado foi qualitativo, buscando traduzir a compreensão de um fenômeno social que é o trabalho em Equipe, a partir da Teoria das 
Representações Sociais, e quantitativo, já que utiliza a dimensão consensual e partilhada expressada na quantidade e qualidade do material apreendido (Gomes, Souza, Minayo, \& Silva, 2005).

Os participantes da pesquisa foram 134 servidores de uma universidade pública e duas universidades privadas do estado do Rio de Janeiro, sendo que 120 participaram exclusivamente da etapa de evocação e 14 participaram de entrevistas em profundidade, além da etapa de evocação. Como critério de inclusão da amostra foi considerado o nível de escolaridade de ensino médio concluído e a assinatura do termo de consentimento livre e esclarecido. No caso da etapa de evocações, houve ainda o critério de inclusão de no máximo de três pessoas de uma mesma equipe de trabalho para maior diversificação dos dados. Na etapa das entrevistas, esse critério era de no máximo uma pessoa por equipe de trabalho.

Como critério de exclusão da amostra na etapa de evocação, consideraram-se os questionários com mais de $30 \%$ das questões em branco e não houve critério de exclusão para a entrevista. Em ambas as etapas, os partici- pantes tiveram resguardados o direito de sigilo das informações prestadas, sendo os dados das evocações analisados de maneira agrupada e os depoimentos das entrevistas apresentados sem a identificação nominal dos respondentes. O projeto de pesquisa foi submetido a um comitê de ética, tendo sido aprovado.

A descrição da amostra aponta para um perfil no qual $54,5 \%$ eram servidores de universidade pública e 45,5\% funcionários de universidades privadas, com $65,4 \%$ de mulheres e $44,6 \%$ de homens. A faixa etária dos pesquisados variou de 18 a 65 anos. $\mathrm{O}$ tempo médio de trabalho nas universidades foi de 10,7 anos e o elevado desvio-padrão $(\mathrm{DP}=11,0)$, sugere heterogeneidade em relação ao tempo de serviço.

O perfil dos participantes das entrevistas indica nove participantes do sexo feminino e cinco do sexo masculino, com idade média de 40,2 anos e desvio-padrão de 9,5 anos. A metade dos entrevistados trabalhava em universidade pública e a outra metade em universidades privadas. Foram categorizados como membros de equipes de trabalho dez, dentre os 14 pesquisados. A Tabela 2 apresenta o perfil detalhado dessas pessoas.

Tabela 2.

Perfil dos participantes das entrevistas

\begin{tabular}{lllll}
\hline Pesquisados & Sexo & Idade & Tipo de organização & Condição de trabalho atual \\
Entrevistado 1 & Feminino & 50 & Pública & Trabalha em equipe \\
Entrevistado 2 & Feminino & 27 & Privada & Trabalha em equipe \\
Entrevistado 3 & Feminino & 38 & Pública & Não trabalha em equipe \\
Entrevistado 4 & Masculino & 40 & Privada & Trabalha em equipe \\
Entrevistado 5 & Feminino & 48 & Pública & Trabalha em equipe \\
Entrevistado 6 & Masculino & 54 & Privada & Trabalha em equipe \\
Entrevistado 7 & Masculino & 35 & Privada & Não trabalha em equipe \\
Entrevistado 8 & Feminino & 55 & Pública & Trabalha em equipe \\
Entrevistado 9 & Feminino & 30 & Privada & Trabalha em equipe \\
Entrevistado 10 & Masculino & 28 & Privada & Não trabalha em equipe \\
Entrevistado 11 & Feminino & 44 & Pública & Trabalha em equipe \\
Entrevistado 12 & Feminino & 31 & Pública & Trabalha em equipe \\
Entrevistado 13 & Masculino & 37 & Privada & Não trabalha em equipe \\
Entrevistado 14 & Feminino & 46 & Pública & Trabalha em equipe \\
\hline
\end{tabular}


Foram aplicados dois instrumentos de coleta de dados: um questionário estruturado e um roteiro de entrevista semiestruturada. No primeiro, foram incluídas perguntas de caracterização sociodemográfica além do termo indutor "trabalho em equipe", sendo solicitadas duas tarefas consecutivas. A primeira pedia que fossem listadas até cinco palavras ou expressões que viessem à mente quando mencionado o referido termo indutor. A segunda tarefa consistia na ordenação dessas palavras e expressões de acordo com o grau de importância atribuído a essas em termos de sua relação com o "trabalho em equipe" (triagens hierarquizadas sucessivas).

No roteiro de entrevista, foram apresentadas sete perguntas abertas as quais objetivavam conhecer as representações que as pessoas constroem acerca do trabalho em equipe. Esse roteiro era semiestruturado, podendo o pesquisador incluir novas perguntas a partir das respostas obtidas de cada entrevistado.

A análise de dados da etapa de evocação considerou as respostas após a ordenação (segunda tarefa), devido ao fato de essa etapa ter mais presente o elemento cognitivo na escolha. Após o agrupamento inicial das palavras de significado semelhante, foi dada continuidade na análise com apoio do software EVOC, que agrupou as palavras mais frequentes no núcleo central e no sistema periférico, conforme será discutido nos resultados.

A análise de dados das entrevistas buscou focar na expressão, análise temática e interpretação do material coletado (Minayo, 2006). Esse estudo não abrangeu a totalidade das falas e expressões dos interlocutores porque, em geral, a dimensão sociocultural das opiniões e representações de um grupo que tem as mesmas características, costuma ter muitos pontos em comum ao mesmo tempo em que apresentam singularidades próprias da biografia de cada interlocutor (Gomes et al., 2005).

O processo de análise das entrevistas partiu da leitura inicial (leitura flutuante) dos depoimentos, tendo sido anotadas impressões preliminares. Uma nova leitura detalhada dos depoimentos levou a um relacionamento destes aos resultados obtidos na análise de representações sociais, de tal forma que as entrevistas permitiram um aprofundamento dos resultados obtidos na etapa de evocação.

\section{Resultados e Discussão}

Da tarefa de evocação de palavras a partir do termo indutor trabalho em equipe, obteve-se um total de 393 palavras, com média de três palavras por participante. Uma análise inicial das palavras evocadas resultou em um total de 187 palavras/expressões distintas. Dessa lista inicial, foi feita uma aglomeração por similaridade de conteúdo. Nessa etapa, foram juntadas palavras ou expressões com significado muito próximo (por exemplo: ajuda/ajudar; ágil/agilidade; objetivocomum/propósito-comum; etc.), o que resultou em uma listagem de 105 palavras evocadas para trabalho em equipe.

Para a análise dos resultados obtidos a partir do método das triagens hierarquizadas sucessivas, foram consideradas somente as palavras que tivessem uma frequência mínima de dez citações, o que levou a um conjunto de 15 palavras mais frequentes nas evocações, as quais correspondem a apenas $14,3 \%$ do total de palavras (105 palavras diferentes após categorização por similaridade), mas a $70 \%$ do total de evocações (frequência de 275 evocações do total de 393).

Além das frequências, o programa EVOC também calculou a ordem média de evocação de cada palavra como a média das ordens em que ela fora evocada pelos diversos sujeitos, atribuindo-se peso "1" a uma evocação em primeiro lugar, peso "2" quando se tratava da segunda evocação do sujeito e assim por diante. Dessa forma, quanto mais próximo de 1 essa média tivesse, maior seria a indicação da importância que os sujeitos atribuíram a essa palavra a partir do termo indutor trabalho em equipe. 
Assim, foi utilizada a combinação desses dois critérios (frequência de evocação e ordem média de evocação de cada palavra/expressão) a fim de possibilitar o levantamento daquelas que provavelmente pertencem ao núcleo central das representações sociais. No caso da presente pesquisa, as palavras nesse núcleo seriam cooperação, respeito e união - todas com uma frequência bem acima (entre 38 e 40) da média (19) das quinze palavras analisadas e uma ordem de evocação acima da média geral de evocações $(2,7)$.

Figura 1: Quadro de quatro casas da análise de evocações do termo indutor trabalho em equipe

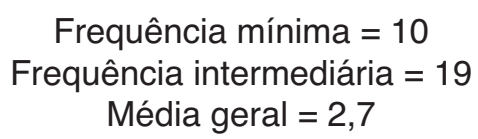

Média $<2,7$

$\begin{array}{llll}\frac{\sigma}{N} & \text { Cooperação } & 38 & 2,29 \\ \frac{\sigma}{0} & \text { Respeito } & 38 & 1,58 \\ \frac{\mathscr{d}}{\mathbb{d}} & \text { União } & 40 & 2,36 \\ \frac{0}{0} & & & \\ \frac{\mathbb{d}}{\leftarrow} & & & \end{array}$

\begin{tabular}{|c|c|c|}
\hline Companheirismo & 17 & 2,12 \\
\hline Comprometimento & 12 & 2,67 \\
\hline Comunicação & 12 & 2,08 \\
\hline Esperança & 15 & 2,40 \\
\hline Organização & 18 & 2,39 \\
\hline Parceria & 12 & 2,17 \\
\hline Participação & 10 & 2,40 \\
\hline
\end{tabular}

Média $\geq 2,7$

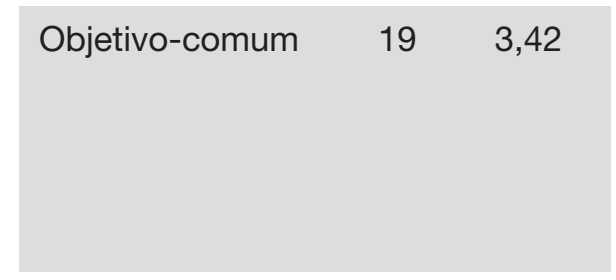

Amizade

$11 \quad 3,82$

Colaboração

$13 \quad 2,92$

Compreensão

15

2,73

Paciência

10

3,10

Resultado

16

Uma análise dessas palavras mostra que "união" foi a palavra de maior frequência (40), porém, dentre as três que estariam no núcleo central, é a que possui ordem média de evocação mais elevada $(2,4)$, sinalizando que houve uma tendência de evocar outras palavras diante do termo indutor trabalho em equipe antes de se falar em "união". Em relação às entrevistas, a palavra "união" também esteve presente em alguns depoimentos, normalmente apresentada como uma característica e uma vantagem do trabalho em equipe. Alguns entrevistados usaram diretamente a palavra "união", e outros usaram expressões delas derivadas como "unindo" ou "unidade". A seguir, os depoimentos que citaram a palavra "união" ou suas derivadas.

- "As vantagens do trabalho em equipe são cooperação, objetivos, determinação, união" (Entrevistado 5).

- "A equipe é a união entre todos, onde todos estão motivados com o trabalho" (Entrevistado 9). 
- "Penso que a vantagem seria o entrosamento de todos os envolvidos no projeto/atividade, unindo esforços à busca do alcance aos objetivos, o trabalho fica mais fácil quando ele é dividido e compartilhado por todos" (Entrevistado 3).

- "O trabalho feito em equipe tem a expectativa de ser mais integrado e mesmo quando há uma divisão de tarefas, elas são interligadas porque a equipe trabalha com uma maior unidade, conhecendo as funções de todos" (Entrevistado 2).

- "Embora em uma equipe as pessoas sejam mais autônomas, considero que um líder consiga dar uma unidade ao todo e diluir pequenos conflitos que possam atrapalhar o trabalho" (Entrevistado 2).

A palavra "cooperação" também foi bastante frequente (38) e teve uma ordem média de evocação próxima da obtida pela palavra "união" (2,3), ficando, portanto, no quadrante referente ao núcleo central. Nas entrevistas, apareceu poucas vezes a palavra "cooperação". Um dos entrevistados mencionou cooperação e união como vantagens do trabalho em equipe (como visto nos depoimentos listados acima). O Entrevistado 14 afirmou que: "a cooperação é fundamental para o trabalho em equipe".

Por fim, no núcleo central, a palavra "respeito" é a que mais se destaca nas evocações que partiram da expressão trabalho em equipe, uma vez que combina frequência alta de evocações (38), com uma priorização da mesma na ordenação das palavras/expressões evocadas a partir do termo indutor (ordem de evocação média de 1,6). Nas entrevistas, a palavra "respeito" não foi mencionada diretamente, mas foram utilizadas derivações do verbo respeitar (respeitem, respeitarem, respeitam), como pode ser visto a seguir.

- "Para uma equipe de trabalho funcionar bem é preciso um bom líder, pessoas que se gostem e se respeitem e tenham ética" (Entrevistado 1).
- "Para uma equipe funcionar bem, acredito que todos os integrantes têm que ter a mesma empolgação com a causa, respeitarem as diferentes visões, verem os colegas como colaboradores e não como competidores e buscarem em conjunto soluções práticas que visem sempre a eficácia da ação e assim o bem-estar do usuário do serviço" (Entrevistado 11).

- "No trabalho em equipe as pessoas se ajudam, se respeitam e se envolvem com um objetivo comum. Já no trabalho em grupo as pessoas se reúnem para dar conta de uma tarefa, mas não tem garantia de um envolvimento genuíno" (Entrevistado 1).

Como elemento de primeira periferia - considerado aqueles que têm uma frequência igual ou superior à frequência intermediária (19), embora com uma ordem de evocação média abaixo da média geral, tem-se uma única expressão objetivo comum. Nenhuma outra palavra figurou nesse quadrante de análise.

Embora não tenha figurado no núcleo central das representações sociais acerca do trabalho em equipe, a expressão "objetivos comuns" foi bastante mencionada nas entrevistas realizadas, seja de forma literal ou com termos similares como "objetivo do coletivo", "objetivo maior", "interesse comum", "objetivo geral" ou "um mesmo objetivo". A seguir, são apresentados depoimentos dos pesquisados em que essa expressão emerge.

- "O trabalho rende, tem melhor qualidade, tendo em vista que as pessoas envolvidas têm um interesse comum" (Entrevistado 6).

- "No trabalho em equipe as pessoas se ajudam, se respeitam e se envolvem com um objetivo comum" (Entrevistado 1).

- "O trabalho em grupo nem sempre os objetivos são comuns e em equipe, todos trabalham com a mesma finalidade." (Entrevistado 6). 
- "Cuida-se para que o objetivo geral da seção não se perca" (Entrevistado 13).

- "Há desvantagens no trabalho em equipe quando (...) um membro quer estar mais em evidência do que o outro, deixando que o brilho do ego ofusque o objetivo do coletivo" (Entrevistado 3).

- "O trabalho em equipe busca o mesmo objetivo, as habilidades são complementares na busca de objetivos comuns, já no trabalho em grupo as habilidades não se complementam" (Entrevistado 10).

- "Partindo de nossa realidade cotidiana o trabalho em equipe visa a um objetivo maior e geral de nossa unidade administrativa e técnica para o qual todos colaboram" (Entrevistado 14).

Um conjunto expressivo de palavras figurou na zona de contraste. Enquanto a zona de primeira periferia teve apenas uma palavra, constaram na zona de contraste sete palavras. Por ordem de importância para os sujeitos, essas palavras foram: comunicação $(2,1)$; companheirismo $(2,1)$; parceria $(2,2)$; organização $(2,4)$; esperança e participação (ambos com 2,4); e comprometimento $(2,7)$. As palavras "companheirismo", "parceria", "esperança" e "participação" não apareceram de forma espontânea nas entrevistas. Porém, as palavras "comunicação", "organização" e "comprometimento" foram citadas pelos pesquisados em diferentes trechos. A seguir, são apresentados os depoimentos em que aparecem essas três palavras que figuraram na zona de contraste.

- "Me sinto bem com relação a equipe de trabalho, que é composta por pessoas acessíveis e há bastante comunicação" (Entrevistado 6).

- "As principais diferenças do trabalho em equipe e sozinho é que em equipe temos feedback e concretização de objetivos, embora também aconteça falhas na comunicação e desempenho" (Entrevistado 1).
- "Para a equipe funcionar é preciso haver comunicação clara das questões pertinentes e colaboração." (Entrevistado 13).

- "Na equipe era preciso que houvesse mais organização, inclusive da minha parte" (Entrevistado 8).

- "O que eu considero que é importante para uma equipe de trabalho funcionar bem é comprometimento, sinceridade, presença, diálogo..." (Entrevistado 3).

- "Se eu pudesse mudaria a motivação dos colegas de forma que aumentasse o comprometimento com a equipe" (Entrevistado 11).

Na zona denominada de segunda periferia - caracterizada por elementos que tiveram tanto a frequência quanto a importância mais baixas -, estão as palavras: compreensão $(2,7)$; colaboração $(2,9)$; paciência $(2,9)$; resultado $(3,7)$ e amizade $(3,8)$. Desse conjunto, as palavras "paciência" e "amizade" não foram mencionadas em nenhuma das quatorze entrevistas realizadas. Já as palavras "compreensão", "colaboração" e "resultado" estiveram presentes nos depoimentos, como pode ser visto a seguir:

- "Entrosamento, educação, desigualdade, compreensão, carinho e amor pelo que faz e com quem faz" (Entrevistado 5).

- "Equipe é quando existe compreensão entre todos e o trabalho em grupo é quando o serviço é feito por obrigação" (Entrevistado 9).

- "É preciso haver comunicação clara das questões pertinentes e colaboração." (Entrevistado 13).

- "Os colegas de trabalho são colaborativos." (Entrevistado 11).

- "O trabalho em equipe visa a um objetivo maior e geral de nossa unidade administrativa e técnica para o qual todos colaboram" (Entrevistado 13). 
- "Com colaboração, a execução fica mais rica" (Entrevistado 14).

- "É preciso ver os colegas como colaboradores e não como competidores" (Entrevistado 11).

- "Para a equipe funcionar bem é preciso colaboração" (Entrevistado 4).

- "Creio que o trabalho em grupo o foco é a tarefa, enquanto e equipe, o importante é o resultado" (Entrevistado 12).

- "Na equipe é preciso ter como foco o resultado final." (Entrevistado 2).

Nessa pesquisa, foi possível observar que palavras como: "cooperação", "respeito" e "união" estão presentes no quadrante do núcleo central. Possivelmente, essa visão de equipe pode estar relacionada à cultura paternalista brasileira que tende a ver as organizações de trabalho como uma "família" (Colbari, 1997).

Como elemento de primeira periferia figurou o termo objetivo-comum. Vale destacar que a ideia expressa por esse termo está presente na maior parte das definições de trabalho em equipe (Arrow \& McGrath, 1995; Katzenbach \& Smith, 2001; Moscovici, 1994; Sikes, Gulbro, \& Shonesy, 2010). Nesse sentido, poder-se-ia esperar que o termo constasse até mesmo como núcleo central. Vale inclusive destacar que ele esteve presente na maior parte das entrevistas, sendo bastante comum a associação do trabalho em equipe com metas/propósitos/objetivos comuns. De qualquer forma, o fato de figurar na primeira zona de periferia, confere ao termo relativo destaque, uma vez que as palavras que esse quadrante indica são os elementos periféricos mais importantes (Abric, 2003).

No que diz respeito à zona de contraste, na qual são encontrados elementos com baixa frequência, mas considerados importantes pelos sujeitos, houve um expressivo número de elementos que incluiu as seguintes palavras: comunicação, companheirismo, parceria, or- ganização, esperança, participação e comprometimento. Como a zona de contraste pode "revelar elementos que reforçam as noções presentes na primeira periferia ou a existência de um subgrupo minoritário portador de uma representação diferente" (Abric, 2003, p. 64), os elementos presentes nesse quadrante precisam ser analisados com atenção. A respeito desses elementos, vale dizer que quatro deles foram frequentes nas entrevistas, a saber: companheirismo, parceria, participação e comprometimento. As palavras comunicação, organização e esperança, embora constantes da zona de contraste, não foram recorrentes nos discursos dos pesquisados.

Um dado interessante, contudo, é o fato de a palavra organização que figurou na zona de contraste, embora tendo sido pouco frequente no discurso dos entrevistados, consta da lista das principais palavras evocadas na pesquisa de Mourão e Galinkin (2008) acerca do gerenciamento feminino de equipes de trabalho. O mesmo acontece com a palavra compreensão, que na presente pesquisa figurou como elemento de segunda periferia e que esteve no núcleo central da pesquisa de Mourão e Galinkin (2008).

Além da palavra compreensão, também figuraram na zona de segunda periferia da pesquisa as palavras colaboração, paciência, resultado e amizade. Vale destacar que o termo resultado tão presente nos conceitos de trabalho em equipe (Guerra, 2002; Hackman, 1987; Moscovici, 1994) e nas justificativas organizacionais para a opção por esse tipo de organização do trabalho, figure apenas na zona de segunda periferia.

\section{Considerações finais}

Entender como as pessoas percebem o trabalho em equipe e que tipo de representações sociais são construídas em torno desse objeto pode contribuir para se obter uma visão mais abrangente dos problemas relativos ao fenômeno e, consequentemente, uma com- 
preensão da realidade, reduzindo a distância entre contexto e ação. Nesse sentido, este trabalho trouxe uma contribuição no avanço da pesquisa sobre equipes de trabalho, com destaque para os seguintes resultados: há um amplo conjunto de palavras evocadas a partir do termo indutor "trabalho em equipe"; as palavras que estão no núcleo central quando se usa o termo indutor "trabalho em equipe" são: cooperação, respeito e união, todas com uma frequência bem acima da média do conjunto de palavras e com uma ordem de evocação acima da média geral de evocações, sendo "união" a palavra de maior frequência; como elemento de primeira periferia, tem-se uma única expressão "objetivo comum", enquanto na zona de segunda periferia estão as palavras: compreensão, colaboração, paciência, resultado e amizade; um conjunto expressivo de palavras figurou na zona de contraste. Por ordem de importância para os sujeitos, essas palavras foram: comunicação, companheirismo, parceria, organização, esperança, participação e comprometimento.

Como a pesquisa tinha caráter descritivo, sua relevância e validade está voltada para a ampliação da compreensão acerca do fenômeno trabalho em equipe e não propriamente de explicações deste. Assim sendo, o estudo permitiu compreender melhor como os atores categorizam e interpretam esse fenômeno, sem pretensão de oferecer informações sobre como atuar na gestão de equipes.

Para estudos futuros acerca dessa temática, sugere-se a realização de pesquisas com amostras mais abrangentes e diversificadas, com possíveis comparações de resultados por setores de atuação, uma vez que o trabalho em equipe pode ser visto de maneira distinta, por exemplo, entre profissionais da saúde e esportistas. Outra ideia seria a pesquisa das representações sociais sobre equipes de trabalho em equipes com diferentes tipos de liderança, uma vez que a atuação dos líderes pode influenciar a percepção que os membros desenvolvem acerca do trabalho em equipe.

Assim, tem-se clareza que, no que diz respeito às equipes de trabalho, ainda há muito a ser pesquisado. O presente estudo, embora dando alguma contribuição acerca de como as equipes de trabalho são vistas por determinada categoria ocupacional, suscita também muitas indagações a respeito dessa temática. Fica, portanto, o convite para a que o trabalho em equipe continue sendo investigado.

\section{Denise de Aragão Fernandes dos Santos}

Mestre em Psicologiapela Universidade Salgado de Oliveira - Educadora organizacional na Universidade Federal Fluminense - dafsantos@hotmail.com.

\section{Luciana Mourão}

Doutora em Psicologia - Professora permanente do Mestrado e Doutorado em Psicologia da UNIVERSO - mourao.luciana@gmail.com

\section{Luciene Alves Miguez Naiff}

Doutora em Psicologia - Professora permanente do Mestrado em Psicologia da UFRRJ lunaiff@hotmail.com

\section{Endereço para envio de correspondência:}

Rua Presidente Backer, 234 - apto 1002 - Bloco A - Icaraí - CEP 24220-041 - Niterói - RJ.

Recebido 05/05/2013, Aprovado 29/07/2014 


\section{Referências}

Abric, J. C. (1994). Pratiques sociales et représentations. Paris: Presses Universitaires de France.

Abric, J. C. (1998). A abordagem estrutural das representações sociais. In A. S. P. Moreira, \& D.C. Oliveira (Orgs.), Estudos interdisciplinares em representações sociais (pp. 27-38). Goiânia, GO: AB Editora.

Abric, J. C. (2001). O estudo experimental das representações sociais. In D. Jodelet (Org.), As Representações Sociais. Rio de Janeiro: Ed. UERJ.

Abric, J. C. (2003). Abordagem estrutural das representações sociais: desenvolvimentos recentes. In P. H. F Campos, \& M. C. da S. Loureiro (Orgs), Representações sociais e práticas educativas (pp. 37-57). Goiânia, GO: UCG Editora.

Arrow, H., \& McGrath, J. (1995). Membership dynamics in groups at work: a theorical framework. Research in Organizational Behavior, 17, 373-411.

Bejarano, V. C, Pilatti, L. A, Scandelari, L., \& Oliveira, A. C. (2006). Equipes virtuais - um estudo de caso na indústria têxtil norte-americana. Produção, 16(1), 161-170. doi: http://dx.doi.org/10.1590/S010365132006000100013

Brandt, J. A., Oliveira, I. C. (2009). Análise das relações dos supervisores com suas equipes nas organizações de trabalho. Psicologia USP, 20(4), 577-596. doi: http://dx.doi.org/ 10.1590/S0103-65642009000400006

Colbari, A. (1997). Familismo e Ética do Trabalho: O Legado dos Imigrantes Italianos para a Cultura Brasileira. Revista Brasileira de História, 17(34), 53-74. doi: http://dx.doi.org/ 10.1590/S0102-01881997000200003

Flament, C. (1994). Aspects périphériques des représentations sociales. In C. Guimelli (Ed.), Structures et transformations des représentations sociales (pp. 85-118). Lausanne, Switzerland: Delachaux Niestlé.
Gomes, R., Souza, E. R., Minayo, M. C. S., \& Silva, C.F.R. (2005). Organização, processamento, análise e interpretação de dados. Rio de Janeiro: Fiocruz.

Guerra, A. V. (2002). Desenvolvimento de Equipes: uma abordagem através de tecnologias da educação à distância. Dissertação de Mestrado em Engenharia de Produção, Universidade Federal de Santa Catarina, Florianópolis.

Guzzo, R. A., \& Dickson, M. W (1996). Teams in organizations: recent research performance and effectiveness. Annual Review of Psychology, 47, 373-411.

Guzzo, R. A., \& Shea, G. P. (1992). Group performance and intergroup relations in organizations. In M.D. Dunnette \& L.M. Hough (Eds.), Handbook of Industrial and Organizational Psychology (pp. 269-313). New York: Prentice-Hall.

Hackman, J. (1987). The design of work teams. In J. Lorsch (Ed.), Handbook of Organizational Behavior (pp. 315-342). New York: PrenticeHall.

Hoegl, M., \& Parboteeah, K. P. (2006). Team reflexivity in innovative projects. $R \& D$ Management, 36(2), 113-125. doi: 10.1111/j.14679310.2006.00420.x

Katzenbach, J. R., \& Smith, D. K. (2001). Equipes de alta performance: conceitos, princípios e técnicas para potencializar o desempenho das equipes. Rio de Janeiro: Campus.

Matos, E., Pires, D. E. P., \& Campos, G.W.S. (2009). Relações de trabalho em equipes interdisciplinares: contribuições para reinstituições de novas formas de organização de trabalho em saúde. Revista Brasileira de Enfermagem, 62(6), 863-869. doi: http://dx.doi.org/ 10.1590/S0034-71672009000600010 
Marqui, A. B. T., Jahn, A. C., Resta, D. G., Colomé, I. C. S., Rosa, N., \& Zanon, T. (2010). Caracterização das equipes da Saúde da Família e de seu processo de trabalho. Revista da Escola de Enfermagem da USP, 44(4), 956-961. doi: http://dx.doi.org/10.1590/S008062342010000400014

Minayo, M. C. S. (2006). O Desafio do Conhecimento: Pesquisa Qualitativa em Saúde (9a ed.). São Paulo: Hucitec.

Montanari, R. L., Pilatti, L. A., Lima, I. A. de, \& Romano, C. A. (2011). A maturidade e o desempenho das equipes no ambiente produtivo. Gestão \& Produção, 18(2), 367-378. doi: http://dx.doi.org/10.1590/S0104530X2011000200011

Moscovici, S. (1994). Equipes que dão certo: a multiplicação do talento humano. Rio de Janeiro: José Olympio.

Mourão, T. M. F., Galinkin, A. L. (2008). Equipes gerenciadas por mulheres: representações sociais sobre gerenciamento feminino. Psicologia: reflexão e crítica, 21(1), 91-99. doi: http://dx.doi.org/10.1590/S010279722008000100012

Puente-Palácios, K. E., Almeida, R. S., \& Rezende, D. V. (2011). O impacto da interdependência no trabalho sobre a efetividade de equipes. Organizações \& Sociedade, 18(59), 605-623. doi: http://dx.doi.org/10.1590/S198492302011000400003
Puente-Palacios, K. E., \& Borges-Andrade, J. E. (2005). O efeito da interdependência na satisfação dos membros das equipes de trabalho: um mundo multinível. Revista de Administração Contemporânea, 9(3), 57-78. doi: http://dx.doi.org/10.1590/S141565552005000300004

Rodrigues, D. F., Johann, M. E. P., Cunha, N. M. M. da, \& Macêdo, I. I. de. (2003). Aspectos comportamentais da gestão de pessoas. Rio de Janeiro: Editora FGV.

Silva, N. (2009). Conflitos intragrupos: Preditores e consequentes no cenário de equipes de trabalho. Dissertação, Psicologia Social, do Trabalho e das Organizações (PSTO), Universidade de Brasília, Brasília, DF.

Sikes, J. B., Gulbro, R. D., \& Shonesy, L. (2010). Conflict in work teams: problems and solutions. Proceedings of the Academy of Organizational Culture, Communications and Conflict, 15(1), 48-52.

Souza, M. G. S. de, \& Puente-Palacios, K. E. (2011). A influência do autoconceito profissional na satisfação com a equipe de trabalho. Estudos de Psicologia, (Campinas) 28(3), 315325. doi: http://dx.doi.org/10.1590/S0103166X2011000300003 